International Journal of English Language and Literature Studies

$\operatorname{ISSN}(e): \quad 2306-0646$

$\operatorname{ISSN}(p): \quad 2306-9910$

DOI: $10.18488 / 5019 . v 1111.4409$

Vol. 11, No. 1, 16-30.

(C) 2022 AESS Publications. All Rights Reserved.

URL: www.aessweb.com

\title{
AMALGAMATING BLOOM'S TAXONOMY AND ARTIFICIAL INTELLIGENCE TO FACE THE CHALLENGES OF ONLINE EFL LEARNING AMID POST-COVID-19 IN SAUDI ARABIA
}

\section{Albatool Abalkheel}

\author{
Department of English Language and Translation, College of Arabic Language and Social Studies, \\ Qassim University, Buraydah, Kingdom of Saudi Arabia. \\ Email:a.abalkheel@qu.edu.sa
}

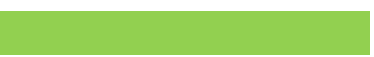

Article History

Received: 12 October 2021 Revised: 17 December 2021 Accepted: 4 January 2022

Published: 20 January 2022

\section{Keywords}

Artificial intelligence

Bloom's taxonomy

COVID-19

Digital Bloom

EFL

Online.

\begin{abstract}
During the coronavirus pandemic, remote learning offered instructors numerous potential opportunities to implement online applications for the success of students' language proficiency. Despite this, there has been a rise in the number of challenges that afflicted EFL Saudi instructors and their learners from attaining sustainable development. The core purpose of this work was to explore these complexities and provide suggestions on how Saudi EFL instructors could adapt while maintaining learners' cognitive and psychological well-being. Furthermore, it questioned the extent to which artificial intelligence (AI) and Bloom's digital taxonomy (BDT) played an innovative role in improving Saudi educational quality and effectiveness. To this end, a qualitative study design was embraced, consisting of a meta-analysis of the most recent studies conducted on the topic of study. The findings indicated that despite having gained access to platforms and apps led by technology, EFL instructors faced numerous challenges such as inadequate training, incompetence, restricted accessibility, poor web infrastructure, modest technological assistance, low motivation, and attention to deficit learners. Thus, AI and BDT may help bridge the gaps and overcome some of the pandemic's challenges. This study provided recommendations for curriculum designers, developers, and policymakers, on the challenges of e-learning systems and how to address them during the pandemic and afterward.
\end{abstract}

Contribution/ Originality: This study is one of the very few studies which have investigated the increased amount of hurdles that have inhibited EFL Saudi teachers and their students from achieving sustainable development during COVID-19 through an amalgamation of artificial intelligence and Bloom's digital taxonomy.

\section{INTRODUCTION}

The world is increasingly becoming interconnected due to globalization, making it crucial for Saudi learners to develop the appropriate productive skills that can enable them to communicate effectively. Numerous challenges deter Saudi learners from gaining mastery of the language (Alharbi, 2020). These are often classified as intrinsic and extrinsic educational factors that are deemed to be the most critical because they influence personal and social well-being (Alahmadi \& Alraddadi, 2020).

In the educational sector, instructors play an active role in enabling learners to learn English as a foreign language (Hakim, 2020). With the coronavirus outbreak, instructors faced unprecedented difficulties: they were unprepared; they had to adjust to the new demands of technology in order to embrace the distance learning mode adopted by educational institutions (Jiang, Zhang, \& May, 2019). In this regard, it was crucial to empower the instructors by investing in their students' cognitive skills, developing and revising the higher form of thinking 
patterns such as inferring and analyzing concepts, instead of automation and rote memorization (Lee, Watson, \& Watson, 2020).

Noticeably no one can afford to stop the digital transformation in the educational sector and the wave of change that machine learning was causing (Ja'ashan, 2020). Hence, there was a need to build capacity of learners and educators alike to exploit the full potential of online education in the post-pandemic educational sector. Not long ago, in 2020, the Saudi Press Agency (www.spa.gov.sa) had reported that the Kingdom of Saudi Arabia aimed to become the world leader in AI by 2030. It brought together leading educational professionals and providers of technology to plan for a new strategy, suggest and find solutions that will exorbitantly scale-up competitiveness, interactivity creation, and a promising educational setting for Saudi alpha generation.

\subsection{Problem Statement}

When questioned about their low EFL achievement, many Arab learners attributed their failures to the challenges imposed by the online learning environment (Rahman, 2020). They found it challenging to employ grammatically correct sentences (Ahmed, 2020). Their errors in writing, for example, were due to interference from the mother tongue and inadequate practice of writing skill. Previous research also indicated many other problems like overall low reading proficiency and comprehension (Farooq \& Soomro, 2018).

Furthermore, many Saudi learners lacked the required reading habits and found it difficult in many areas, including scanning, vocabulary usage, and skimming. As the coronavirus pandemic prevailed, the intricacies encountered by EFL learners and instructors further exacerbated (Al Lily, Ismail, Bunasser, \& Alqahtani, 2020). This phenomenon necessitated many teaching institutions with weak technical infrastructure and incompetent instructors in digital pedagogy to embrace this sudden shift (Almaiah, Al-Khasawneh, \& Althunibat, 2020). Such institutions faced impediments such as technological adoption, intimidating feedback issues, and lack of necessary resources.

During the course of the coronavirus disease, the Kingdom of Saudi Arabia: Vision 2030 (2021) could globally position itself as the new face of digital transformation and economic reforms. Digital transformation in KSA was responsible to transform the lives of its citizens (Almurayh, 2021). Learners felt more comfortable with smartphones and tablets rather than traditional textbooks (Alnujaidi, 2021). Despite the transformation, disparities needed to be bridged between teachers and information communication technology (ICT). If teachers lacked computer-assisted language learning (CALL) expertise, transferring knowledge to students would become a challenge.

\subsection{Research Questions}

This work addresses the following questions:

1. What challenges have been encountered during the integration of technology into EFL learning amid the outbreak in the Kingdom of Saudi Arabia?

2. Is Bloom's digital taxonomy practical if adapted in online teaching?

3. To what extent does artificial intelligence' integration help address the challenges of the EFL teachinglearning process throughout the COVID-19crisis?

\subsection{Significance of Study}

The Kingdom of Saudi Arabia: Vision 2030 (2021) indicated that vision 2030 would help improve and advance Saudi Arabian's governmental schools and universities which are correlated with the advancement of the English language. Yet, the efficacious execution of vision 2030 relies on the productive preparation of various academic instructors, which necessitates improving their EFL skills. By completing this study, policymakers, learners, administrators, and instructors would possibly consider how they can play a successful part in guaranteeing and 
incorporating technology into web-based learning, without hampering the advancement made in understanding and teaching EFL. Furthermore, this study urged the need to facilitate the coordination between instructors and counselors to provide quality distance learning and establish equity in terms of educational opportunities postCOVID-19. This work may likewise contribute significant knowledge and present critical practical insights on how artificial intelligence coupled with Bloom's digital taxonomy can play a pivotal role in imparting knowledge and skills on how Saudi Arab learners can improve their EFL skills.

\section{LITERATURE REVIEW}

\subsection{Online Learning as an Abrupt Change of the Learning Technique with the Outbreak}

Online learning was seen as an option in contrast to traditional face-to-face learning, yet this has changed because of the COVID pandemic. It turned into a need for the support of educational infrastructure (Fitri \& Putro, 2021). This digitally-mediated archetype has led to changes in the way instructors think about teaching differently before the spread of pandemic (Alkinani, 2021). Past research on bringing technology to EFL classrooms has featured a few factors that affect the teaching or learning process. According to Alahmadi and Alraddadi (2020) technology-led classes continue to become more popular among EFL instructors who are receptive to change in their teaching methods for better techniques that can accrue benefits to the learners positively impact learning and teaching. It is challenging for EFL learners and instructors to cope with the new language teaching theories.

Today, many instructors prefer to deploy digital materials such as motion pictures, online documentaries, audios, presentations, and videos rather than traditional papers and worksheets. Powerful utilization of technological interaction apparatuses can help both instructors and learners by accessing vital resources and aiding learning (Gao \& Zhang, 2020). Specialized interaction tools are also critical for improving collaboration with experts, learners, and instructors globally, thus paving the way for understanding the language through multimedia (Mantiri, Hibbert, \& Jacobs, 2019). Peer informal learning for EFL instructors also has a positive and significant impact on the technology assimilation process (Ma, Chutiyami, Zhang, \& Nicoll, 2021).

However, being digitally illiterate causes difficulties in coordinating with appropriate tactics while attempting to use technology. Furthermore, the absence of technical support prevents typical technical maintenance from occurring, resulting in a larger likelihood of failures developing in this sector (Almaiah et al., 2020).

\subsection{Learners' Cognitive Well-Being}

Besides principal challenges which impede the integration of technology, there are also elements like low levels of motivation, inefficient network connection, inadequate training, attention deficit, limited technical support, educators' ineptitude, and limited time. According to Saylor (2020) equality and inclusiveness must be prioritized as important elements of the teaching profession. This must always be the case; yet, with the COVID-19 epidemic, several challenges arise in the complicated components that instructors must address. The psychological and cognitive well-being of learners is at the top of the list (Goranova, 2019). If online learning is to be maintained effectively and productively, Bloom's taxonomies of educational objectives must be embraced in online EFL classes or traditional offline classes. The original taxonomy presented six major categories, which can be mastered based upon prerequisites in the reflective zone classified from lower to higher-order thinking skills: knowledge, comprehension, application, analysis, synthesis, evaluation (Figure 1).

There were attempts (Anderson \& Krathwohl, 2001) to replace Bloom's taxonomy with a revised one to provide clear and specific details about the teaching-learning process. They altered the prototype taxonomy in three significant schemes: idioms, arrangement, and prominence. Among the six levels, three (remembering, understanding, creating) were provided a different designation (Knowledge, comprehension, synthesis), and two of the titles' thinking orders (evaluation, synthesis) were rearranged to denote action words instead of nominative 
ones (Wedlock \& Growe, 2017). Like the old taxonomy, the modified version disposed of a stratum with each phase connected to the preceding as a proviso (Figure 2 ).

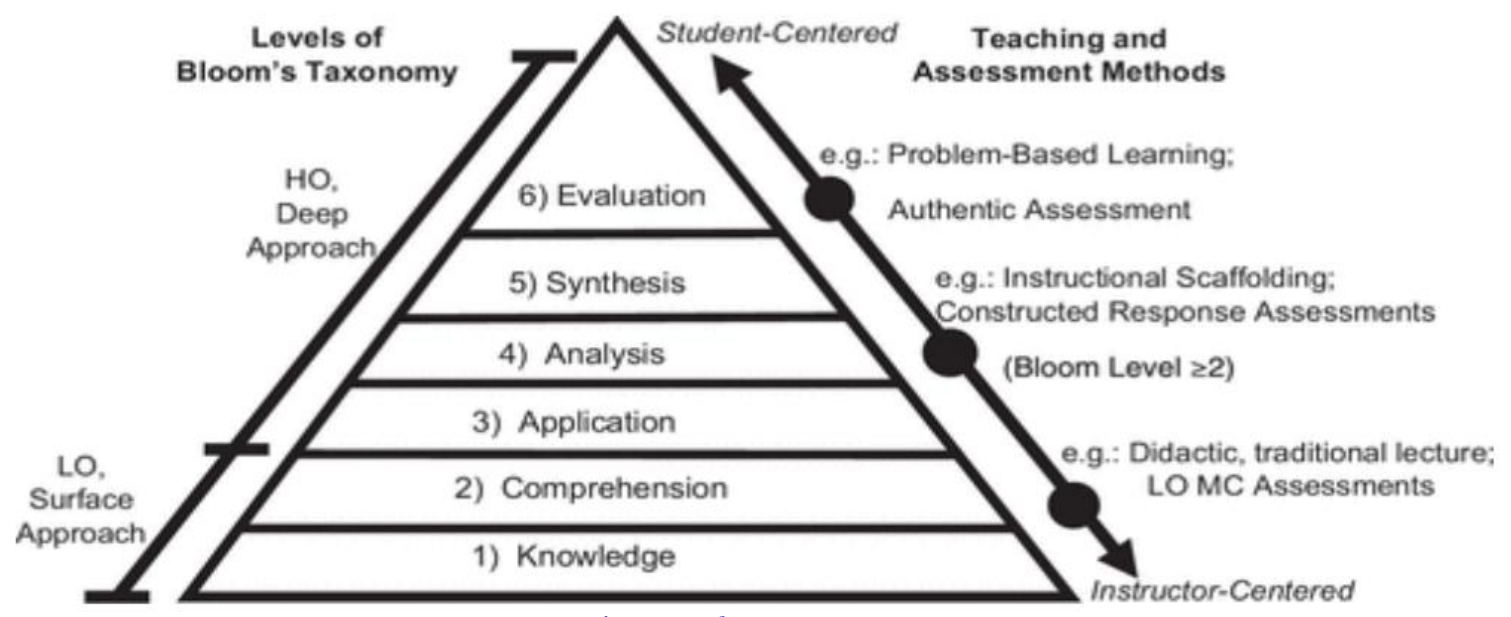

Note: Lower order (LO), higher-order (HO) thinking skills.

Figure 1. Bloom's taxonomy

Adapted from: Hobbins, Murrant, Snook, Tishinsky, and Ritchie (2020) https://journals.physiology.org/doi/full/10.1152/advan.00126.2019.

\section{HIGH LEVEL THINKING SKILLS}

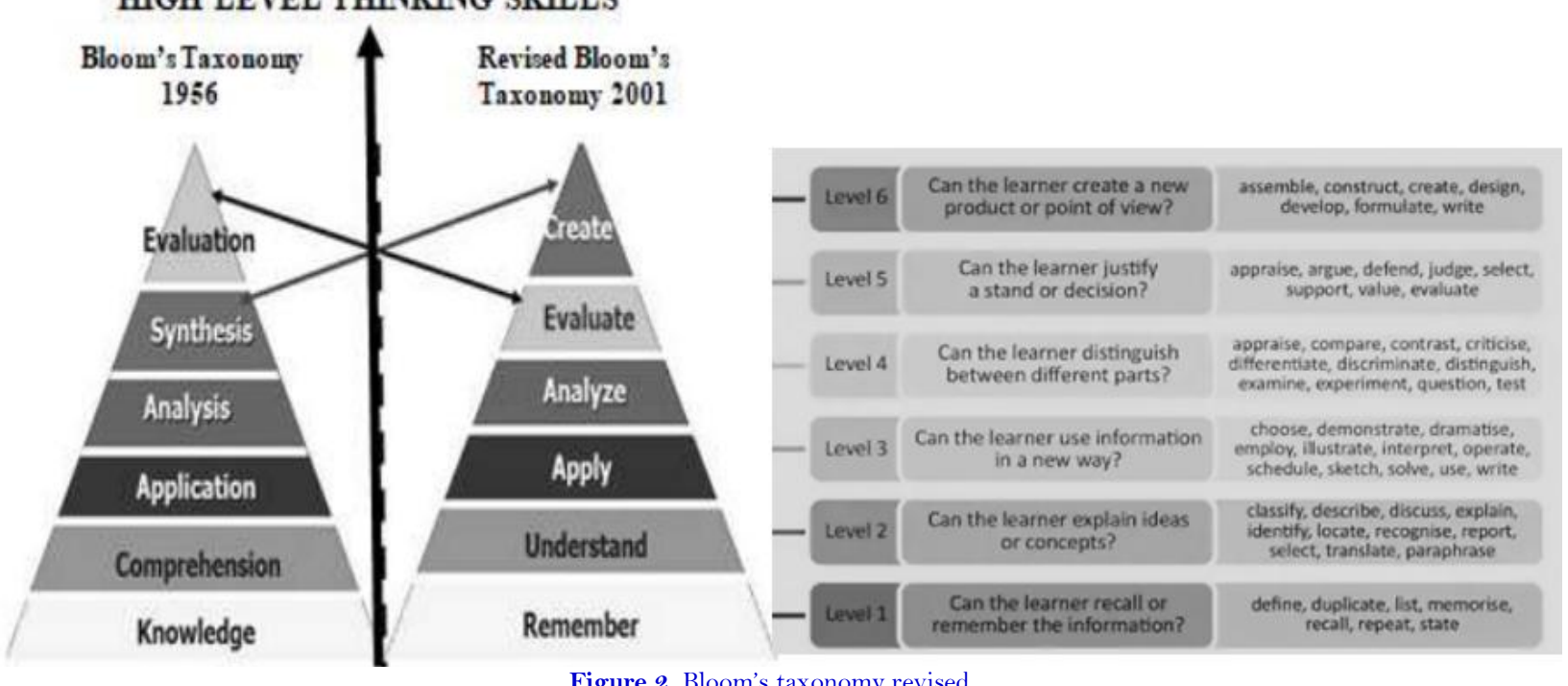

Figure 2. Bloom's taxonomy revised.

Note: Adopted and modified from Mahmud, Yunus, Ayub, and Sulaiman (2019)

Thus, fostering higher-order thinking will set out principles for apprentices to determine intellectual standards such as: "clarity, precision, accuracy, relevance, depth, breadth, logicalness, significance, and fairness" (Paul \& Elder, 2013). As a consequence, the EFL skills will be integrated equally and systematically.

\subsection{Artificial Intelligence}

There have been ongoing debates about what and how to define Artificial intelligence (AI), despite its momentum (Sajja, 2021). Yet, they all seem to hold a standard view about AI: It is an area covering the study of a wide variety of computer science that seeks to build intelligent machines capable of mimicking 'intelligent' tasks typically performed by humans (Ciolacu, Tehrani, Binder, \& Svasta, 2018). Currently, researchers found deficiencies connected to AI usage in the educational sector (Bécue, Praça, \& Gama, 2021). As they explored this sector in the Arab World, scholars found that the employment of AI is posing challenges when it comes to data safety. Its use has also resulted in many other problems, including instructors' resistance to change, lack of instructors' learners' preparedness, and ability to effectively integrate AI into learning settings (UNESCO, 2019). 
Duan, Edwards, and Dwivedi (2019) noted many factors that impeded the successful incorporation of technology in the education sector in the Middle East, and efforts were made to slow down technology adoption outside Gulf economies. Only factors contributing to AI development can determine the levels at which such technology is adopted; these include poor infrastructure necessary to adopt AI and insufficient skills to do so in the education sector.

A few experts (Woolf, Lane, Chaudhri, \& Kolodner, 2013) discussed and categorized the intriguing challenges that kept them from integrating Artificial Intelligence with remote EFL teaching: organizational (lack of support and cooperation when developing and adopting technologies for better remote EFL teaching and complex fares for improving and applying systems or keeping the current situation); political (technology integration into the existing curriculum, providing the needs of both teachers and learners, ensuring that they all adhere to the use of AI by boosting their motivation) (Bostrom \& Yudkowsky, 2014); technical challenges and those necessary to provide continuous feedback (refer to the need to incorporate and integrate critical pedagogy across all user platforms) (Frankish \& Ramsey, 2014), and in addition to strenuous tasks revolving around the need to regularly update ethical issues of confidentiality, data privacy, and subject matter.

Experts are still looking for an effective model to agree upon when integrating AI into education (Ciolacu et al., 2018). They believe that as the current framework seems unsystematic, its immersion could lead to non-fulfillment rather than achievement. Despite looking for the appropriate method, there has been very little research on how to effectively integrate such technology into education (Bécue et al., 2021). While AI has been embraced in other sectors in the Middle East, it has not yet been fully integrated into teaching in the region. If completely immersed, AI will impact the entire area, particularly the region around the UAE (Halaweh, 2018).

\section{METHODOLOGY}

3.1. Study Design

To gain insight, explore the intensity and search intricacy imminent, the researcher selected a qualitative study design, particularly a systematic review method ideally suiting the to address the research questions (Figure 3). A systematic review summarizes the research literature on one situation to facilitate the identification, selection, appraisal, and synthesis of high-quality research evidence (Mengist, Soromessa, \& Legese, 2020).

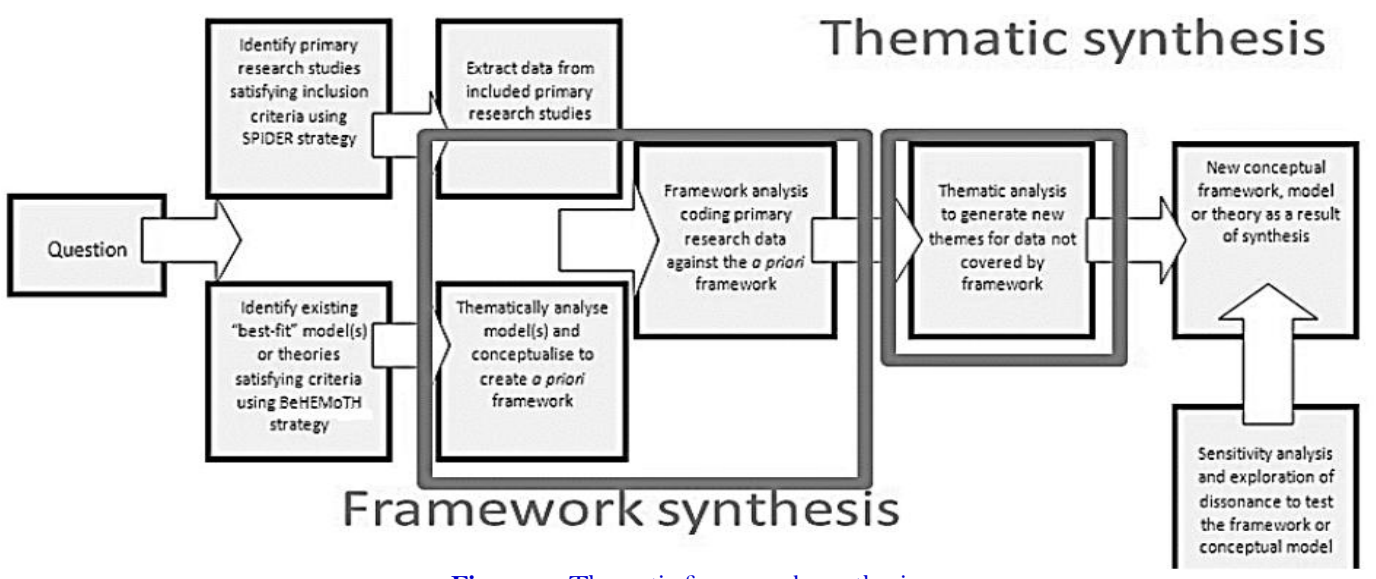

Source: Garside (2010)

Figure 3. Thematic framework synthesis.

Systematic reviews, if appropriately done, can minimize inherent bias and obtain the best quality information. It also adheres to a well-defined protocol indicating concepts, objectives, and procedures to synthesize available evidence and reach reliable conclusions. The other rationale for using the systematic review technique is that it can enable the study to tackle the specific research questions, obtain accurate and reliable results, and comprehensively review all the available data (Xiao \& Watson, 2019). The systematic review can provide a detailed and 
straightforward overview of the available evidence on challenges faced by EFL instructors and learners throughout COVID-19 scenario. After completion of work, a researcher is able to refine the knowledge on the research topic, come up with new research ideas and gain critical skills in the synthesis of the existing literature.

This research is framed in the theory of Bloom's taxonomy and the connectivist approach because it "presents a model of learning that acknowledges the tectonic shifts in society where learning is no longer an internal, individualistic activity" (Siemens, 2005). Instead, it acts as the beginning point of learning and feeds the information into a network that relays it back to individuals to take it back into the network. Having technologies, networks, and connectivity part of communication activities begins to change the communication theories into the digital age. Therefore, there is a need for coining or engaging connectivist learning theory to communication theories amidst the pandemic.

\subsection{Data Collection}

A research protocol for a systematic literature review is essential for ensuring its features: transferability, transparency, and replicability. It helps in reducing bias by carrying out comprehensive literature searches. In the review, ascertaining the research scope is the most daunting issue. Accordingly, Zotero, an open-access reference management tool, served to "build a personal library of source information from articles, books, documents, web pages, and more” (Research Guides: Zotero, n.d). It, furthermore, allowed to collect, organize, cite, and share various sources of research.

This work adopted major elements for systematic reviews and meta-analyses (PRISMA) embraced by Moher, Liberati, Tetzlaff, Altman, and Group (2009) to address the study's research questions. The process entailed four main stages: identification, screening, eligibility, and inclusion. During the identification, the number of articles was pinned down while searching in online databases. In the screening phase, duplication Figure 4 was selected to remove duplications $($ number $=326)$ and identify the more relevant articles.

\begin{tabular}{|c|c|c|c|c|}
\hline Z Zotero & & & & - \\
\hline $\begin{array}{l}\text { Ele Edit View Iools Help } \\
0 \text {. }\end{array}$ & 0.8100 .8 .18 & $\rho \cdot$ Title, C & Creator, 1 & 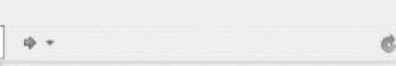 \\
\hline Business English & Item Type Year & Publication & . Is... $\mathrm{m}$ & Merge 6 items \\
\hline Challenges & 2 Connectivism: Learning theory of th... Journal Arti... 2008 & The International Re... & 3 & \\
\hline Cognitive Challenges & > Connectivism: Learning theory of th... Journal Arti... 2008 & The International Re... & 3 & $\begin{array}{l}\text { Choose the version of the item to use as } \\
\text { the master item: }\end{array}$ \\
\hline Connectivism & ? E Connectivism: Learning theory of th... Journal Arti... 2008 & The International Re... & 3 & \\
\hline Ba Digital Bloom Taxon... & An exploratory study of the obstacl... Journal Arti... 2020 & Education Sciences & 9 & $1,7: 22: 59 \ldots$ \\
\hline Distance learning du... & (E) An exploratory study of the obstacl... Journal Arti... 2020 & Education Sciences & 9 & 3/29/2021, 7:30:17 ... \\
\hline EFL Saudi Arabia & > Challenges of e-Learning during th... Journal Arti... 2020 & Arab World English ... & 4 & $5: 11 \ldots$ \\
\hline Exploratory Action R... & 2 E Challenges of e-Learning during th... Journal Arti... 2020 & Arab World English ... & 4 & 3/29/2021, 9:08:15 ... \\
\hline KSA vision 2030 & , Online teaching-learning in higher ... Journal Arti... 2020 & International Journa... & & 3/29/2021, 9:13:47 ... \\
\hline PRISMA & , Enline Teaching-Learning in Higher... Journal Arti... 2020 & International Journa... & & 3/29/2021, 9:14:24 ... v \\
\hline Qualitative Research & A Systematic Review on Mathemati... Journal Arti... 2020 & Eurasia Journal of M... & 8 & Select fields to keep from other versions \\
\hline Self Efficacy & E A Systematic Review on Mathemati... Journal Arti... 2020 & Eurasia Journal of M... & 8 & \\
\hline Thematic Systematic & , Distance learning in vocational hig... Journal Arti... 2020 & Indonesian Journal ... & 2 & Type Journal Article \\
\hline Zotero & s. Distance learning in vocational hig... Journal Arti... 2020 & Indonesian Journal ... & 2 & Title EFL Teachers' \\
\hline My Publications & , Distance learning in vocational hig... Journal Arti... 2020 & Indonesian Journal ... & 2 & Challenges and \\
\hline$\therefore$ Duplicate Items & > Online Learning amidst Global Pan... Journal Arti... 2020 & ENGLISH FRANCA: ... & 2 & ssights of Online \\
\hline Unfiled Items & , Online Learning amidst Global Pan... Journal Arti... 2020 & ENGLISH FRANCA: ... & 2 & $\begin{array}{l}\text { Teaching amidst } \\
\text { Global Pandemic }\end{array}$ \\
\hline â Tench & v EFL Teachers' Challenges and Insig... Journal Arti... 2021 & Metathesis: Journal ... & 3 & Author Nugroho, Arif \\
\hline & 2EFL Teachers' Challenges and Insig... Journal Arti... 2021 & Metathesis: Journal ... & 3 & Author IImiani, Dwi \\
\hline
\end{tabular}

Figure 4. Removing duplicated sources.

During the eligibility phase, articles were assessed, and exclusion was completed for those, not fit in the study's scope. To only include articles needed for final analysis, especially the most relevant, the inclusion stage helped filter those deemed irrelevant. 


\subsection{Search Strategy}

This stage outlined the strategy used for searching and delivery of studies. It is crucial for defining the correct search string and identifying relevant databases for collecting the essential documentation. While the number of systematic literature review databases can be restricted and defined, their number is ascertained by the topic chosen.

PRISMA (Moher et al., 2009) principles were used for carrying out a multidisciplinary search of studies conducted previously to address the research questions. The first strategy entailed finding studies on EFL challenges in the context of EFL, computational linguistics, and Bloom's Taxonomy. The study relied on various databases, including Science Direct, Google Scholar, IEEE, Sage Journals-Sage, Saudi Digital Library, Scopus, Springer, and Elsevier. The search was carried out within the various globally acknowledged databases to gather relevant information in the field study $(\mathrm{n}=3230)$.

Notably, Science Direct is usually an online assemblage of published journals, while the Scopus database consists of peer-reviewed studies from the globe (Mengist et al., 2020). Contrary to the others, Google Scholar fails to offer journal types, publishers, or data regarding time-interval (during the pandemic). However, it is an advanced search engine for covering citations not found in additional databases $(n=20)$. It is worth noting that every database needs to be searched, while the publications and date of acquisition are mentioned. The search string is also used for accessing chosen databases to collect many related study papers. Application of the search string within selected databases ensures that the number of available studies is revealed $(n=3250)$.

Moreover, the forms and size of databases utilized to search corresponding publications can ascertain the specimen deployed for research. Before assembling the primary methodical research, a preliminary exploration was attempted to ensure that search keywords were refined to cover the study's objectives (COVID-19, KSA vision 2030, connectivist, EFL challenges, digital Bloom, distance learning).

What is more, testing was done for various search strategies, such as review of abstracts, addition or deletion of different research terms, and manual searching. A particular set of words was chosen to generate the most relevant results in linguistics and education $(\mathrm{n}=151)$. Besides, the reference lists of selected papers were carefully scanned to collect more relevant studies. In order to the study's research questions, the assessment was also completed to evaluate the selected data through the method presented in Figure 5.

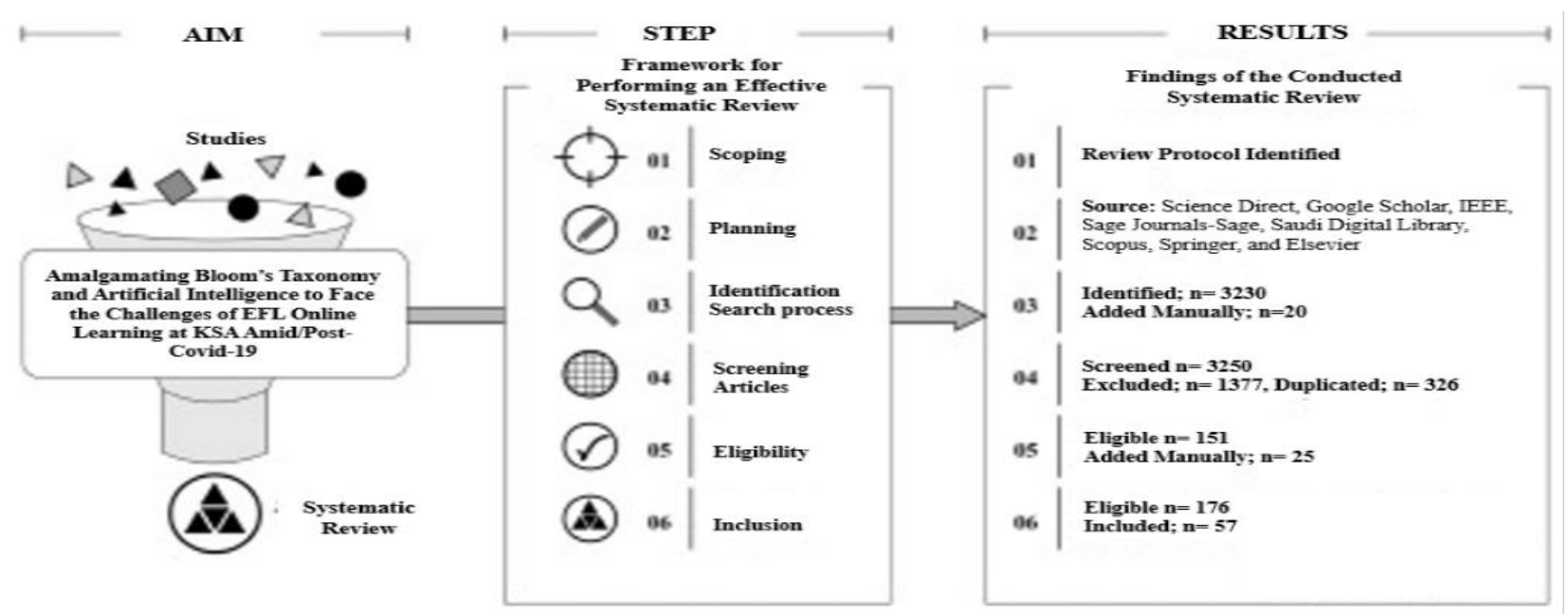

Figure 5. PRISMA flow diagram.

Note: $\mathrm{N}=$ number. Adapted and modified from Liu et al. (2020).

The selection of data meant screening the selected literature to identify the suitable and relevant papers for the review work. This search led to the generation of 3,250 studies that were minimized to 1,873 studies after removing duplicates. After screening of records, 1,377 studies were excluded, leading to 176 full-text articles. These data were then assessed regarding the inclusion/exclusion criteria mentioned above, leading to 57 references. 


\subsection{Eligibility Criteria}

Studies that met the inclusion criteria were chosen to go through further content assessments and investigation by applying the exclusion and inclusion criteria. After completing the initial search strategy, identification of studies to be incorporated was made following the following criteria: The studies which were included had to be carried out in Saudi Arabia, focusing on the EFL teaching-learning process, artificial intelligence, etc., most preferably be published between 2018 and 2021 (pre and mid pandemic), be peer-reviewed journals, cover educational settings, and have appropriate methodologies, including qualitative method.

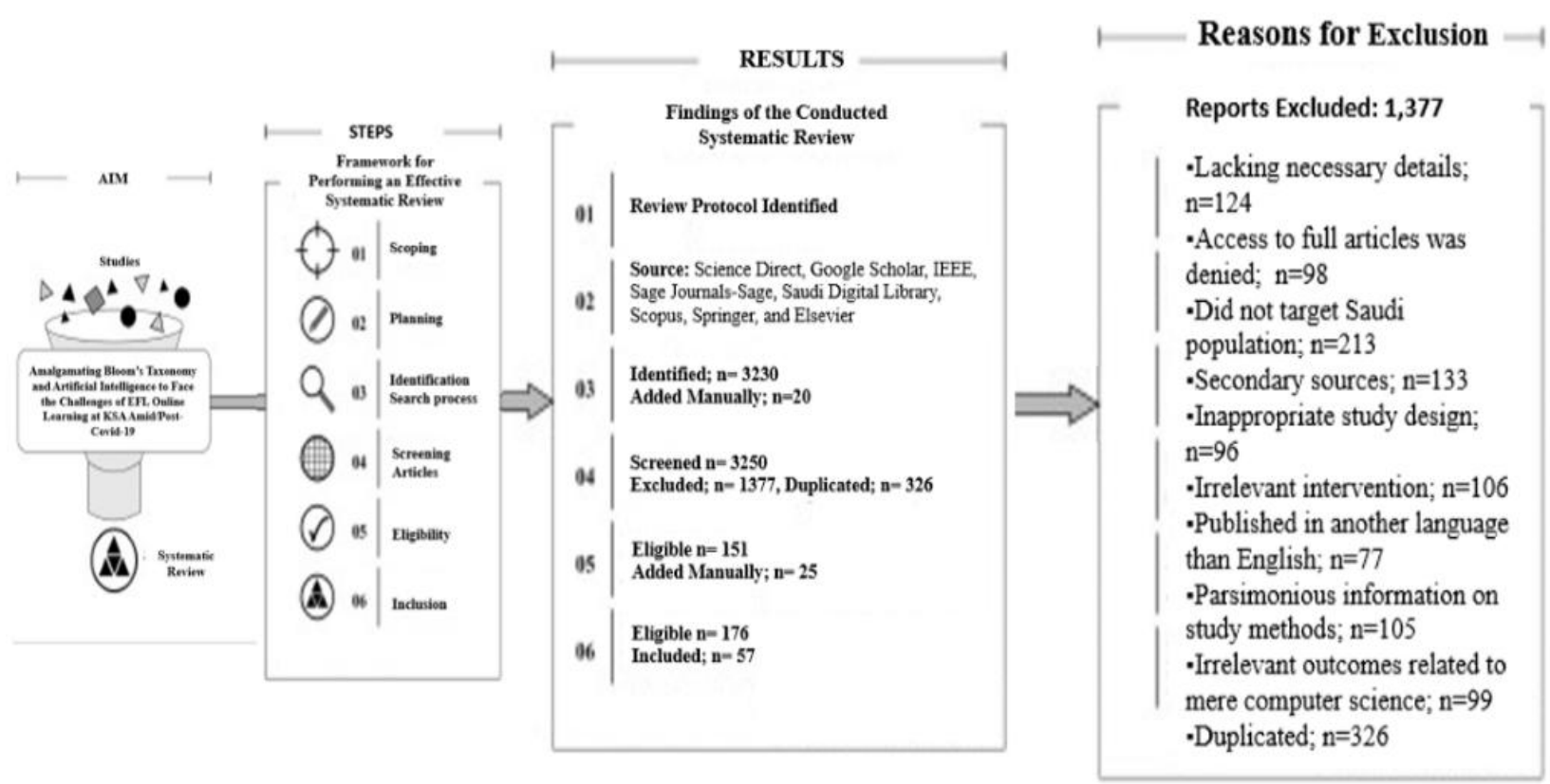

Figure 6. Eligibility criteria: Inclusion and exclusion of data.

Everything else fell under the umbrella of the exclusion criteria Figure 6, above: lack of necessary details $(n=124)$, access to full articles was denied $(n=98)$, did not target Saudi population $(n=213)$, secondary sources $(\mathrm{n}=133)$, inappropriate study design $(\mathrm{n}=96)$, irrelevant intervention $(\mathrm{n}=106)$, published in another language than English $(n=77)$, parsimonious information on study methods $(n=105)$, irrelevant outcomes related to mere computer science $(n=99)$, and duplicated sources $(n=326)$.

\subsection{Synthesis}

This step was made up of classification and extraction of data from chosen studies to obtain knowledge and inferences. The extraction process entailed identifying and extracting relevant data from selected papers to ensure that the research obtained focused on precise results. To tackle the study's objectives, general article characteristics were organized, and particular parameters were utilized for evaluating, quantifying, or mapping the studies. The classification step entailed categorizing and processing data obtained to prepare for further analysis where final results from the information obtained in articles are presented.

\subsection{Analysis}

This stage involved evaluating the synthesized data and extracting critical information. It encompassed quantitative and qualitative explanation of results, discussing, and making conclusions. Data obtained are summarized as inferential or descriptive statistical techniques. For this study, descriptive data helped in presenting trends of publications and making inferences. 


\subsection{Report}

This stage entailed describing and presenting methods then results were obtained. This section was structured around two significant phases: explaining and describing the primary process followed and publicly showing the results in a journal article. The information obtained from the systematic literature review is presented in the following section on findings and discussions.

\section{INTERPRETATION OF PRINCIPAL FINDINGS}

\subsection{Technical Complexities}

To answer the first question raised in this research, among the impediments identified was the likelihood of technical difficulties (Alahmadi \& Alraddadi, 2020). For instance, within the virtual learning settings, which depend on video, one common aspect is that Saudi students report lagging or delays, which can potentially minimize the interaction's effectiveness (Almaiah et al., 2020). Previous research has demonstrated that the delays experienced in techno-mediated learning environments show that. In contrast, these forms of delays tend to be ubiquitous. EFL learners were able to maintain the meaning and develop L2 learning strategies for handling difficulties they may encounter (Hakim, 2020).

It can be anticipated that enhancing internet speed and the state of technology can reduce technical delays (AlSaleh, 2018). Technical difficulties can still minimize some level of participation of interaction among EFL learners. This finding was replicated by Khan, Radzuan, Shahbaz, and Ibrahim (2018) when they argued that the use of technology, particularly smartphones, is vital for language learning. Still, the challenges of limited memory and battery life impeded the use of these gadgets. What is more, many instructors understand the process of accessing the Internet for deployment in teaching and learning English. Still, only a few of them have sufficient training for integrating technology into their teaching (Vlasova, Avksentieva, Goncharova, \& Aksyutin, 2019).

Overall, Saudi Arab specialists in education need to pay considerable attention to all the barriers to using CALL tools efficiently in teaching (Ma et al., 2021). Infrastructure, policy, planning, support, and management are essential factors that help in integrating CALL successfully, but they are non-teacher-related components (Mantiri et al., 2019). Critical factors associated with teachers cannot be overlooked to maintain the integrity of ICT in the process of teaching and learning (Khan et al., 2018).

\subsection{Preparation Deficiency}

Still, within the realm of the first question raised, researchers noted that the academic challenges encountered by Saudi EFL teachers include the administration of online assignments and the creation of learning content. EFL teachers are so far overwhelmed with routing business and upskilling-related tasks (Almaiah et al., 2020). The Saudi teaching cadre spends more time preparing and actualizing online courses, leading to job dissatisfaction and frustration. This time factor also has a detrimental impact on learners if not handled appropriately in online learning (Farooq \& Soomro, 2018).

Yet, technology integration enhances a student-centered approach to learning, and automated planning enables EFL students to improve and manage their regulation skills significantly within the online learning environment (Alsmari, 2020; Lee et al., 2020). Even with feasible technology, practical training remains one of the significant reasons which impedes Luddite teachers from integrating technology into teaching (Al-Saleh, 2018; Alnujaidi, 2021 ; Farooq \& Soomro, 2018). Practical training remains a significant reason for Luddite teachers to integrate technology into teaching (Alnujaidi, 2021; Farooq \& Soomro, 2018). Researchers' findings maintain that Saudi instructors received inadequate training on teaching and learning methods linked to online learning (Alrouji, 2020; Alsmari, 2020; Rahman, 2020).

Henceforth, professional advancement and continuous technical training sessions for EFL instructors are essential parts of organizational support (Al Lily et al., 2020). EFL instructors need to improve their careers and 
undergo technical training to integrate techno-led platforms and applications in their EFL teaching field (Alkinani, 2021).

\subsection{Social Cognitive Competency}

Responding to the second question raised by this research, Ja'ashan (2020) considered the high demand placed on learners' accountability and achievement. Instructors who perceived that their face-to-face instructional methodologies emphatically affected students' learning were unlikely to merge technology into their practice despite being necessary during this pandemic (Gulnaz, Althomali, \& Alzeer, 2020; Ma et al., 2021). Consequently, Low self-efficacy was identified as another challenge that hampers Saudi EFL instructors from responding to this unexpected teaching alternative mode during the outbreak (Rahman, 2020).

Self-efficacy is likewise attributed to learners with motivation deficiency levels in embracing technology (Lee et al., 2020). Being applauded as an excellent factor for EFL generative performance, motivation is manifested by teacher-learner behavior and is represented as being extrinsic and intrinsic (Locke \& Schattke, 2019). For this situation, intrinsic motivation is considered as central key for the educational process. Evidently, "whenever students' natural curiosity and interest energize their learning and when the educational environment provides optimal challenges, rich sources of stimulation and a context of autonomy, this motivational wellspring in learning is likely to flourish" (Deci \& Rayan, 1985).

It would also be interesting to note that online learners' attention-deficit results from their lack of motivation and the heavy burden placed upon themselves for fulling countless academic tasks (Locke \& Schattke, 2019). Thereby, EFL instructors need to play the role of organizers. They have to offer their students equal opportunities and find immediate solutions if they tackle any distance learning (Fitri \& Putro, 2021). For this reason, instructors are required to develop particular management skills and use CALL as mind tools to refine learners' cognitive skills amidst the COVID-19 pandemic.

These findings are in tandem with the theoretical frameworks advanced before. From the learning theory perspective, technology integration seeks to fulfill sociocultural, constructivist, and connectivist principles (Downes, 2019). In addition to recognizing the cognitive domains, structure to promote higher-order thinking authorizes students' EFL skills to be amalgamated equally and systematically. This requires learners to demonstrate intelligibility and precision, examine the significance, and manifest the potential for in-depth thinking (Goranova, 2019).

Alternatively, instructors apply Bloom's digital taxonomy in the EFL context for teaching the objectives of composing, lecture plan development, online activities' organization, and assessment as a reference to attain their learners' higher-order level of thinking (Wedlock \& Growe, 2017). Thus the impact of Bloom's framework is presumably pertinent as it "stems from its appealing nature and the fact that each level of cognitive sophistication, although designed to transcend specific subject matters and educational stages, can be interpreted and operationalized to suit individual contexts" (Fitzhugh II, 2019).

\subsection{Computational Intelligence}

In the context of societies that will potentially root AI, the last question raised by the researcher is to find out the extent to which findings 'hype' the use of artificial intelligence in EFL teaching. Major studies selected before 2018 do not support the argument that artificial intelligence indorses personalization and better learning outcomes. Duan et al. (2019) contend that artificial intelligence is gaining momentum. While AI has acted as the principal driving force in emerging technologies, it can also pose susceptibilities concerning ethical consideration and the security of students' data (Ciolacu et al., 2018). Yet, it became paramount to refine original skills to build and interpret cyber-programmed technologies. 
As indicated by the International Data Corporation, between 2017 and 2021, there will be more than a 32\% increase in AI technologies in the Arab world (Doucet et al., 2018). Further evidence suggests this will have a significant impact on society in the Middle East. Qatar, Saudi Arabia, and UAE are the areas that have been identified to be strenuously committed to developing and implementing AI technologies (Khan et al., 2018).

Since AI began to sweep across many sectors, "the UNESCO Education Sector is developing initiatives that harness AI to achieve SDG 4, [...] mobilize AI hub centers and hackathons to cascade training for youth across a broader scale" (UNESCO, 2019). Consequently, to respond to the needs of teachers in these modern times, many avant-garde companies are roughly working to develop integrated systems that will allow teachers to implement AI and original programs facilitated by software for better remote learning.

Additional findings highlighted that innovative Chatbots-related apps are helpful for engaging Saudi EFL students in person and collecting information using answers obtained from previous questions to create relevant questions (Almurayh, 2021). Ideally, the bot records all knowledge that had been taught within the lectures. More so, Brainly, Content Technologies Inc, Mika, and Netex -to name a few intelligent tutoring systems-offer personalized constructive learning guidance (Ma et al., 2021). Not to be overlooked, Bloom in the 1970s heralded the productivity of individual learning that became among the coveted targets of AI investigators and experimenters. Furthermore, Trory (2020) claimed: "That machine learning allows us to mark, to assess, freespeaking and free-writing along with listening [ ...] using data from all over the world [...] within 48 hours, that's the really exciting bit" (par.11).

To this end, AI has addressed various aspects of lifelong automated learning. Yet, Instructors' leadership and individuality, allied with AI machine learning devices' framework, are a considerable means to stimulate students' aptitude in their language learning sector.

\section{CONCLUSIONS AND RECOMMENDATIONS}

The current study sought to investigate the challenges afflicted by Saudi EFL instructors and learners that ailed the teaching-learning process during the COVID-19 pandemic. Studies identified various barriers, including technical accessibility, lack of preparedness, virtual facilitation, time management, equity, self-efficacy, and cognitive constraints. Moreover, this study insinuated that the lack of knowledge, experience and training impeded the teaching cadre who advocated and favored the brick-mortar teaching mode to keep abreast digital pedagogy during the outbreak.

Thus, to enhance their professional development, instructors must undergo resilient joint CALL workshops to adapt and utilize technological tools within their EFL classes. They can help Saudi students organize and interpret what they acquire from knowledge using CALL as a cognitive amplification instrument, rather than presenting facts and information with instructional tools. Visualizing devices, intentional information search engines, live conversation environments, and computer conferences are significant illustrations of these tools. Therefore, efficiently integrating CALL helps constructivist learning environments to flourish where students' critical thinking and creativity, including real-world learning, improve. Furthermore, IT education experts must assist Saudi teachers in founding an interactive e-learning environment.

Consequently, when equipped with the necessary tools, skillful instructors need to use these modern and emerging technologies innovatively to facilitate the task of EFL education through encouraging their Saudi learners' higher-order thinking skills. Thus, by connecting the framework of Bloom's revised taxonomy with digital tools, EFL learners will expand their knowledge, skills, and experiment. Instructors find it essential to accomplish the following: incorporate Bloom's taxonomy in their teaching EFL skills, develop course plans, organize online activities, create curricula, and prepare formative/summative assessments as a reference to reach students' higherorder thinking (evaluation, analysis, and creation). Levels foregrounded within Bloom's digital revised taxonomy 
(googling, bullet-pointing, blog journaling, tweeting, uploading, operating, examining, experimenting, arguing, etc.) are embraced iteratively to refine learners' knowledge production and thinking.

Pushing this further, the findings of this study suggest that AI is emerging as a feasible solution for instructors' assistance. First of all, Saudi Arab institutions need to gain insights into how AI is being deployed worldwide to enhance its prospects in the online learning environment. For example, instructors need to improve the quality of feedback in EFL using AI-powered chat robots and natural language processing. Virtual facilitators such as Jill Watson, which promptly responded to students' requests, can be used in the digital domain. Similarly, the chat campus found in Victoria's University of Deakin can be emulated in Saudi Arabia to respond to students' queries. Undauntedly, the time had come when re-orienting pedagogical models became a necessity for educational institutions.

Funding: This study received no specific financial support.

Competing Interests: The author declares that there are no conflicts of interests regarding the publication of this paper.

\section{REFERENCES}

Ahmed, A. O. A. (2020). The effectiveness of the methods in use to promote fluency among EFL learners at foreign languages department, Taif University. European Scientific Journal, 16(11), 1.Available at: https://doi.org/10.19044/esj.2020.v16n11p1.

Al-Saleh, R. S. S. (2018). EFL teacher's attitudes towards blended learning in Tabuk, Saudi Arabia. International Journal of Information Research and Review, 5(1), 5065-5071.

Al Lily, A., Ismail, A., Bunasser, F., \& Alqahtani, R. (2020). Distance education as a response to pandemics: Coronavirus and Arab culture. Technology in Society, 63(1), 101317.Available at: https://doi.org/10.1016/j.techsoc.2020.101317.

Alahmadi, N., \& Alraddadi, B. (2020). The impact of virtual classes on second language interaction in the saudi EFL context: A case study of Saudi undergraduate students. Arab World English Journal, 11(3), 56-72.Available at: https://dx.doi.org/10.24093/awej/vol 11 no3.4

Alharbi, A. (2020). A psychodiscourse analysis of affective aspects of learning experience: A triangulated mixed design. Asian EFL Journal, 27(2), 137-162.

Alkinani, E. A. (2021). Factors affecting the use of information communication technology in teaching and learning in Saudi Arabia Universities. Psychology and Education Journal, 58(1), 1012-1022.Available at: https://doi.org/10.17762/pae.v58i1.849.

Almaiah, M. A., Al-Khasawneh, A., \& Althunibat, A. (2020). Exploring the critical challenges and factors influencing the Elearning system usage during COVID-19 pandemic. Education and Information Technologies, 25, 5261-5280.Available at: https://doi.org/10.1007/s10639-020-10219-y.

Almurayh, A. (2021). The challenges of using Arabic chatbot in Saudi universities. IAENG International Journal of Computer Science, 48(1), 1-12.

Alnujaidi, S. (2021). Adoption of mobile assisted language learning (MALL) in Saudi Arabian EFL classrooms. Journal of Language Teaching and Research, 12(2), 312-323.Available at: https://doi.org/10.17507/jltr.1202.13.

Alrouji, O. O. (2020). The effectiveness of blended learning in enhancing saudi students' competence in paragraph writing. English Language Teaching, 13(9), 72-82.Available at: https://doi.org/10.5539/elt.v13n9p72.

Alsmari, N. (2020). The effect of flipped classroom instruction on developing Saudi EFL learners' comprehension of conversational implicatures. International Journal of English Linguistics, $1 O(2)$, 107-127.Available at: https://doi.org/10.5539/ijel.v 10n2p107.

Anderson, L. W., \& Krathwohl, D. R. (2001). Taxonomy for learning, teaching, and assessing: A revision of Bloom's taxonomy of educational objectives: Longman. 
Bécue, A., Praça, I., \& Gama, J. (2021). Artificial intelligence, cyber-threats and Industry 4.0: Challenges and opportunities. Artificial Intelligence Review, 54(5), 3849-3886.Available at: https://doi.org/10.1007/s10462-020-09942-2.

Bostrom, N., \& Yudkowsky, E. (2014). The ethics of artificial intelligence. In The Cambridge Handbook of Artificial Intelligence (pp. $316-$ 334): Cambridge University Press.

Ciolacu, M., Tehrani, A. F., Binder, L., \& Svasta, P. M. (2018). Education 4.O-artificial intelligence assisted higher education: Early recognition system with machine learning to support students' success. Paper presented at the 2018 IEEE 24th International Symposium for Design and Technology in Electronic Packaging(SIITME).

Deci, E. L., \& Rayan, R. M. (1985). Intrinsic motivation and self-determination in human behavior. Plenum.

Doucet, A., Evers, J., Guerra, E., Lopez, N., Soskil, M., \& Timmers, K. (2018). Teaching in the fourth industrial revolution: Standing at the precipice: Routledge.

Downes, S. (2019). Recent work in connectivism. European Journal of Open, Distance and E-Learning, 22(2), 113-132.Available at: https://doi.org/10.2478/eurodl-2019-0014.

Duan, Y., Edwards, J. S., \& Dwivedi, Y. K. (2019). Artificial intelligence for decision making in the era of Big Data: Evolution, challenges and research agenda. International Journal of Information Management, 48, 63-71.Available at: https://doi.org/10.1016/j.ijinfomgt.2019.01.021.

Farooq, M. U., \& Soomro, A. F. (2018). Teachers and technology: Trends in English language teaching in Saudi Arabia. International Journal of English Linguistics, 8(5), 10-19.Available at: https://doi.org/10.5539/ijel.v8n5p10.

Fitri, Y., \& Putro, N. H. P. S. (2021). EFL teachers' perception of the effectiveness of ICT-ELT integration during the COVID-19 pandemic. Paper presented at the International Conference on Educational Sciences and Teacher Profession (ICETeP 2020). Atlantis Press.

Fitzhugh II, G. (2019). A comparison of complex thinking required by the elementary New Jersey student learning standards and past Nere Jersey curriculum standards. Doctoral Disse Al-Khasawneh rtation, Seton Hall University. Seton Hall University eRepository@Seton Hall Dissertations and Theses (ETDs). 2613.

Frankish, K., \& Ramsey, W. M. (2014). The Cambridge handbook of artificial intelligence: Cambridge University Press.

Gao, L. X., \& Zhang, L. J. (2020). Instructor learning in difficult times: Examining foreign language instructors' cognitions about online teaching to tide over COVID-19. Frontiers in Psychology, 11, 2396.Available at: https://doi.org/10.3389/fpsyg.2020.549653.

Garside, R. (2010). Framework for systematic reviews of qualitative research. Retrieved from https://slideplayer.com/slide/5300949/.

Goranova, E. (2019). Creation of electronic learning objects for the high cognitive levels of Bloom's digital taxonomy. Knowledge International Journal, 31(2), 585-590.

Gulnaz, F., Althomali, A. D. A., \& Alzeer, D. H. (2020). An investigation of the perceptions and experiences of the EFL teachers and learners about the effectiveness of blended learning at Taif University. International Journal of English Linguistics, 10(1), 329-344.Available at: https://doi.org/10.5539/ijel.v10n1p329.

Hakim, B. (2020). Technology integrated online classrooms and the challenges faced by the EFL instructors in Saudi Arabia during the COVID-19 Pandemic. International Journal of Applied Linguistics and English Literature, 9(5), 33-39.Available at: https://doi.org/10.7575/aiac.ijalel.v.9n.5p.33.

Halaweh, M. (2018). Artificial intelligence government (Gov. 3.0): The UAE leading model. Journal of Artificial Intelligence Research, 62, 269-272.Available at: https://doi.org/10.1613/jair.1.11210.

Hobbins, J. O., Murrant, C. L., Snook, L. A., Tishinsky, J. M., \& Ritchie, K. L. (2020). Incorporating higher order thinking and deep learning in a large, lecture-based human physiology course: Can we do it? Advances in Physiology Education, 44(4), 670-678.Available at: https://doi.org/10.1152/advan.00126.2019.

Ja'ashan, M. M. N. H. (2020). The challenges and prospects of using E-learning among EFL students in Bisha University. 
Jiang, L., Zhang, L. J., \& May, S. (2019). Implementing English-medium instruction (EMI) in China: Instructors' practices and perceptions, and learners' learning motivation and needs. International Journal of Bilingual Education and Bilingualism, 22(2), 107-119.Available at: https://doi.org/10.1080/13670050.2016.1231166.

Khan, R. M. I., Radzuan, N. R. M., Shahbaz, M., \& Ibrahim, A. H. (2018). EFL instructors' perceptions on the integration and implementation of MALL in EFL classes. International Journal of Language Education and Applied Linguistics, 8, 39-50.

Kingdom of Saudi Arabia: Vision 2030. (2021). Retrieved from https://www.vision2030.gov.sa/en\#.

Lee, D., Watson, S. L., \& Watson, W. R. (2020). The relationships between self-efficacy, task value, and self-regulated learning strategies in massive open online courses. International Review of Research in Open and Distributed Learning, 21(1), 2339.Available at: https://doi.org/10.19173/irrodl.v20i5.4389.

Liu, Y., Li, N., Zhang, Z., Huang, C., Chen, X., \& Wang, F. (2020). The central trend in crop yields under climate change in China: A systematic review. Science of the Total Environment, 704, 135355.Available at: https://doi.org/10.1016/j.scitotenv.2019.135355

Locke, E. A., \& Schattke, K. (2019). Intrinsic and extrinsic motivation: Time for expansion and clarification. Motivation Science, 5(4), 277-290.Available at: https://doi.org/10.1037/motooo0116.

Ma, K., Chutiyami, M., Zhang, Y., \& Nicoll, S. (2021). Online teaching self-efficacy during COVID-19: Changes, its associated factors and moderators. Education and Information Technologies, 1-23.Available at: https://doi.org/10.1007/s1063902 1-10486-3.

Mahmud, M. S., Yunus, A. S. M., Ayub, A. F. M., \& Sulaiman, T. (2019). Justification on the selection of revised edition of Bloom's taxonomy in the levels of oral questioning in the process of teaching mathematic in Malaysia. International Journal of Innovative Technology and Exploring Engineering, 8(12S2), 586-592.Available at: https://doi.org/10.35940/ijitee.11106.10812s219.

Mantiri, O., Hibbert, G., \& Jacobs, J. (2019). Digital literacy in ESL classroom. Universal Journal of Educational Research, 7, 13011305.Available at: https://doi.org/10.13189/ujer.2019.070515.

Mengist, W., Soromessa, T., \& Legese, G. (2020). Method for conducting systematic literature review and meta-analysis for environmental science research. MethodsX, 7, 100777.Available at: https://doi.org/10.1016/j.mex.2019.100777.

Moher, D., Liberati, A., Tetzlaff, J., Altman, D. G., \& Group, T. P. (2009). Preferred reporting items for systematic review s and meta-analyses: The PRISMA statement. PLoS Medicine, 6(7), eloooo97.Available at: https://doi.org/10.1371/journal.pmed.1000097

Paul, R., \& Elder, L. (2013). Critical thinking: Intellectual standards essential to reasoning well within every domain of human thought. Journal of Developmental Education, 36(3), 1-2.

Rahman, M. M. (2020). Challenges and solutions of teaching English as a foreign language online during a global pandemic like COVID-19: Saudi EFL teachers' perspectives. Journal of Southwest Jiaotong University, 55(6), 1-9.Available at: https://doi.org/10.35741/issn.0258-2724.55.6.10.

Research Guides: Zotero. (n.d). What is zotero? Retrieved from https://guides.nyu.edu/zotero/what-is-zotero.

Sajja, P. S. (2021). Introduction to artificial intelligence. In Illustrated Computational Intelligence (pp. 1-25). Singapore: Springer.

Saylor, V. (2020). 7 ways to make distance learning more equitable. Retrieved from https://www.commonsense.org/education/articles/7-ways-to-make-distance-learning-more-equitable.

Siemens, G. (2005). Connectivism: A learning theory for the digital age. International Journal of Instructional Technology and Distance Learning, 2(1), 3-10.

Trory, S. (2020). How AI-powered language tests can help identify the right talent to hire: Arabian Business Magazine.

UNESCO. (2019). Artificial intelligence in education: Challenges and opportunities for sustainable development. Working Papers on Education Policy, Paris, France. Retrieved from https://en.unesco.org/news/challenges-and-opportunitiesartificial-intelligence-education. 
Vlasova, E. Z., Avksentieva, E. Y., Goncharova, S. V., \& Aksyutin, P. A. (2019). Artificial intelligence-The space for the new possibilities to train teachers. Espacios, 4O(9), 17.Available at: http://dx.doi.org/10.20511/pyr2020.v8nSPE3.719.

Wedlock, B. C., \& Growe, R. (2017). The technology driven student: How to apply Bloom's revised taxonomy to the digital generations. Journal of Education \& Social Policy, 7(1), 25-34.

Woolf, B. P., Lane, H. C., Chaudhri, V. K., \& Kolodner, J. L. (2013). AI grand challenges for education. AI Magazine, 34(4), 6684.Available at: https://doi.org/10.1609/aimag.v34i4.2490.

Xiao, Y., \& Watson, M. (2019). Guidance on conducting a systematic literature review. Journal of Planning Education and Research, 39(1), 93-112.Available at: https://doi.org/10.1177/0739456X17723971.

Views and opinions expressed in this article are the views and opinions of the author(s), International Journal of English Language and Literature Studies shall not be responsible or answerable for any loss, damage or liability etc. caused in relation to/arising out of the use of the content. 